\title{
AUTOMATIC NUMBER PLATE RECOGNITION SYSTEM FOR VEHICLE IDENTIFICATION
}

\author{
Vishnu K.B ${ }^{1}$, Vishnu S.Nair ${ }^{2}$, Rahul C.M ${ }^{3}$, Akhil $\mathbf{J}^{4}$, Gibi Sunny \\ ${ }^{\text {I}}$ Student, Dept. of Electronics \& Communication Engineering, Baselios Thomas I Catholicose College of Engg \& \\ Techonology \\ ${ }^{2}$ Student, Dept. of Electronics \& Communication Engineering, Baselios Thomas I Catholicose College of Engg \& \\ Techonology \\ ${ }^{3}$ Student, Dept. of Electronics \& Communication Engineering, Baselios Thomas I Catholicose College of Engg \& \\ Techonology \\ ${ }^{4}$ Student, Dept. of Electronics \& Communication Engineering, Baselios Thomas I Catholicose College of Engg \& \\ Techonology \\ ${ }^{5}$ Assistant Professor Dept. of Electronics \& Communication Engineering, Baselios Thomas I Catholicose College of \\ Engg \& Techonology
}

\begin{abstract}
The system is designed as the authorized automatic vehicle identifier, for the security of the highly restricted areas. The number plate recognition using the image identification technology is implemented here. Now the technology has developing day by day. Almost in all the human needs fulfillment leads to the generation of new technology. This system can be implemented for the security checking of the highly restricted areas like defense military areas, parliament areas etc. The image of the vehicle is captured by using a camera and processed by the MATLAB. MATLAB is used for the image identification and the number plate extraction. The system contains an embedded section which controls the opening of the security gate and the communication purpose. The LCD screen provided at the entry gate gives visual assistance to the driver, whether he is not permitted at this area or permitted. The entry of the unauthorized vehicle is restricted and the message is send to the security cabin. The communication between MATLAB and the microcontroller is done with zigbee. By incorporating the RTO department database we can have full access to the vehicle's owner and details of the vehicle. The technology which are adopted in this project can be utilized not only for the security but also in other fields such as parking fee collection, vehicle owner identification, etc. The project consists of an embedded section and image identification section. The image identification is done through the MATLAB and the embedded section is programmed using embedded C. Apart from the implementation of the system using RF-ID ,this Project have to be upgraded for the higher security levels. Image identification is the new technology which is adopted in this project.
\end{abstract}

Keywords- components; image identification, number plate extraction, GSM, Zigbee, LCD Display

\section{INTRODUCTION}

Automatic number plate recognition system is the technology in which the numbers of the vehicle is extracted from the vehicle[1]. This can be done by the image identification technique. The system can be implemented in security as well as for the parking fee collection etc. The system can be implemented in the highly restricted areas such as military zones, parliament areas etc. The system consists of a software section and a embedded section. The image from the camera is send to the MATLAB, then the image is further processed to extract the numbers [2]. The databases of the embedded section consist of the authorized vehicle numbers. The embedded system checks the extracted numbers with the data base[2].

\section{SYSTEM EXPLANATION}

The system comprised of an LCD display, GSM module, Zigbee, Alarm system, gate controlling. When an authorized vehicle comes, The MATLAB section sends a particular character "A" along with the extracted number to the embedded section. Then the microcontroller reads the preprogrammed character and the numbers. For an authorized number the microcontroller sends the signal for the gate open also a message is send to the security cabin as "ALLOWED" along with the extracted numbers The LCD screen displays as "ALLOWED". The GSM module is used for the messaging. The entrance of the gate consists of IR sensors to sense whether the vehicle passes through or not. When the vehicle passes, the IR sensor detects and the gate will close automatically.

When an un authorized vehicle comes, the MATLAB section sends another character " $\mathrm{B}$ " along with the extracted number. When the character " $\mathrm{B}$ " is received, then the microcontroller identifies the presence of an un-authorised vehicle. The system then passes the message to the security cabin as "NOT ALLOWED" along with the vehicle number. Then the LCD screen displays as "NOT ALLOWED/UNAUTHORISED VEHICLE ENTRY RESTRICTED" also an alarm will activated at this time and the gate will not open at this time. 
The MATLB section, embedded section and the security cabin are situated at three different locations. Basically the embedded section and the camera is situated near the entry gate. The communication between the MATLAB section and the embedded section is through Zigbee. It is a RF based wireless communication technique. The characters " $A$ ", "B", and the numbers of the number plate from MATLAB are transmitted through Zigbee. The receiver section also contains a Zigbee. The image identification is done by extract each letter/number from the number plate. These characters are stored as images. The database consist of (A-Z) characters and (0-9) numbers and their respective image templates. The extracted images are subjected to compare with the image templates and stores as corresponding text. Thus the numbers from the number plate is identified. Later it is checked with the database for the authorized vehicle list and then the further communication is established through Zigbee.

\section{SYSTEM DESCRIPTION}

\subsection{Basic Block Diagram}

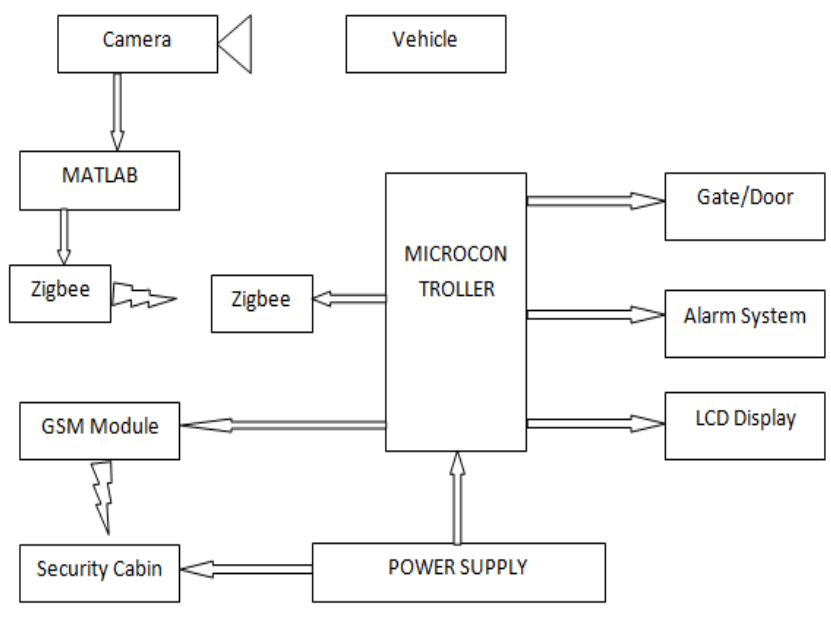

Fig 3 a: Block Diagram

The basic block diagram of the system is shown in Figure III.A. Which includes the embedded and the MATLAB section. The image taken from the camera is shown in figure III.B which is further processed to extract the number. Figure III.C gives the database templates for the number plate extraction. The extracted image is compared with the database templates to convert it into the corresponding text files[3]

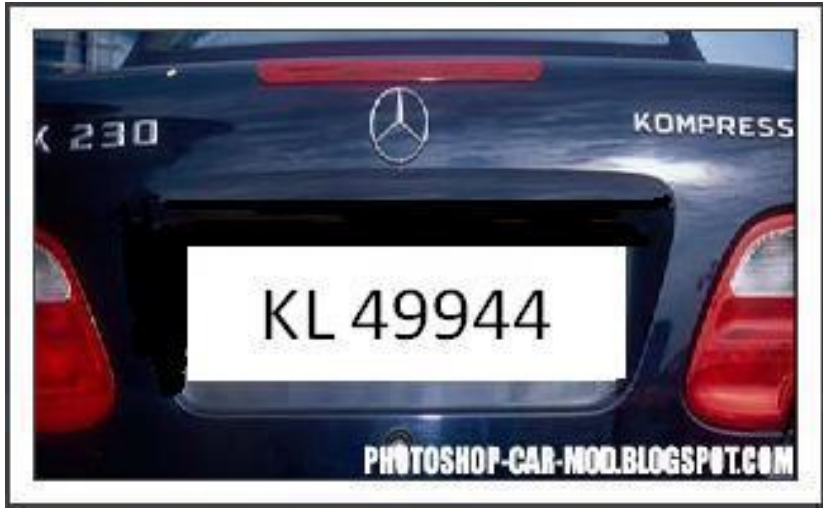

Fig 3b: Captured image of a car
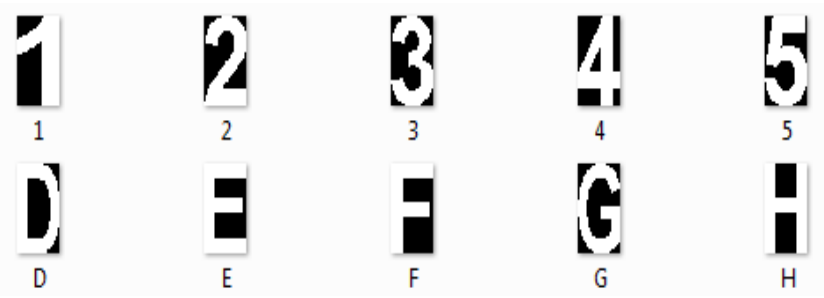

Fig 3c: Database template

\subsection{PIC16F77A}

The microcontroller used for the implementation of the system is PIC16F77A. The microcontroller receives the characters and it controls the entire embedded hardware

\section{Peripheral Features}

a) Timer 0:- 8-bit timer/counter with 8-bit pre scaler

b) Timer 1:-16-bit timer/counter with pre scaler, can be incremented during SLEEP via external crystal/clock

c) Timer 2:- 8-bit timer/counter with 8-bit period register, pre scaler and post scalar

d) It have two Capture, Compare, PWM modules

e) Capture is 16-bit, max. resolution is $12.5 \mathrm{~ns}$

f) Compare is 16-bit, max. resolution is $200 \mathrm{~ns}$

g) The PWM maximum resolution is 10-bit

h) Universal Synchronous Asynchronous Receiver Transmitter with 9-bit address detection.

Table 3a: Device Features

\begin{tabular}{|l|l|}
\hline Key Features & PIC16F877A \\
\hline Operating Frequency & DC - 20 MHz \\
\hline $\begin{array}{l}\text { RESETS } \\
\text { (and Delays) }\end{array}$ & $\begin{array}{l}\text { POR, BOR } \\
\text { (PWRT, OST) }\end{array}$ \\
\hline $\begin{array}{l}\text { FLASH Program Memory } \\
\text { (14-bit words) }\end{array}$ & $8 \mathrm{~K}$ \\
\hline Data Memory (bytes) & 368 \\
\hline Timers & 3 \\
\hline Instruction Set & 35 \\
\hline Serial Communications & MSSP, USART \\
\hline
\end{tabular}




\subsection{LCD Device}

The LCD screen is the output of the system and displays the vehicle to be allowed and it provides the visual assistance to the driver. The LCD module used in this project is a DOGM163W-A that have 3 lines with 16 characters. The LCD Module is assembled with a microcontroller and it is tuned to the white backlight for the better contrast. The LCD Module is connected to the PIC16F77A. The display has 8 bits for data transfer using parallel interface but for the purposes of this project, we only use two terminals out of the 8 data bits because here in this project the data transfer is only through the asynchronous serial transmission. The other data bits are set to high which is $5 \mathrm{~V}$ in this case. The pins of the LCD are connected to thePIC16F77A using a 10 pin header. The figure III.D shows the pin out of the LCD display

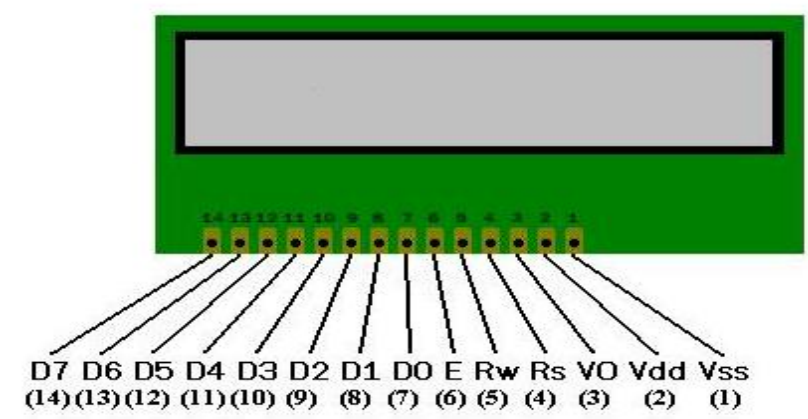

Fig 3d: LCD pin out

\subsection{L293D}

The device is an integrated high voltage ,high current four channel driver designed to accept standard TTL logic levels and drive inductive loads (such as relays, solenoids, DC and stepping motors) and switching power transistors. It can withstand $2 \mathrm{~A}$ of current. Here it is used to drive the DC gear motors used to manage the gate of a compound

To simplify use as two bridges each pair of channels is equipped with an enable input.A separate supply input is provided for the logic, allowing operation at a lower voltage and internal clamp diodes are included.

This device is suitable for use in switching applications at frequencies up to $5 \mathrm{KHZ}$.

The L293D is assembled in a 16 lead package which has 4 center pins which is connected together and used for heat sinking also the s L293D is assembled in a 20 lead surface mount which has 8 center pins connected together for heat sinking.

\subsection{Voltage Regulators (LM 7805)}

Practically all circuits need a power supply. For the efficient working of the electronic devices there must have a constant and smooth dc source. But due to some factors like temperature, impedances etc the constant $\mathrm{dc}$ is not obtained. So by considering these factors we must have to design an efficient dc source which must be constant when any parameters will changes. Here we uses the regulating IC7805 which is shown in figure III.E

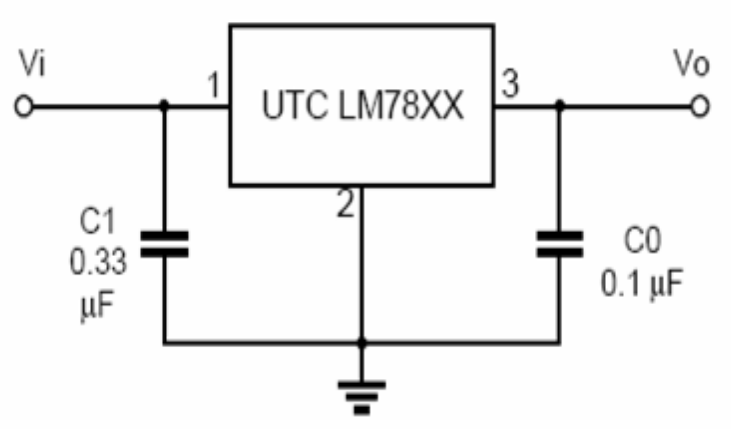

Fig 3e: Voltage Regulator

\section{SYSTEM IMPLEMENTATION}

\subsection{RS-232 Drivers/Receivers}

The RS-232 interface presupposes a common ground between the DTE and DCE. Table IV.A shows the voltage levels of the logic 0 and logic 1.before transmitting and after receiving the data, it is modified by the MAX-232. Electronic data communications between elements will generally fall into two categories, single-ended and differential. This was introduced in 1962, and despite rumors for its early demise, has remained widely used through the industry. The voltage level is shifted to the new level which is shown in table IV.A Channels are established independent for full-duplex communications. The MAX-232 signals are represented by voltage levels with respect to a system common (power / logic ground) and the "idle" state have the signal level negative as common, and the "active" state has the signal level positive with respect to common.

Table 4a: RS-232 Voltage Levels

\begin{tabular}{|c|c|c|}
\hline $\begin{array}{l}\text { RS232 Line Type \& Logic } \\
\text { Level }\end{array}$ & $\begin{array}{l}\text { RS232 } \\
\text { Voltage }\end{array}$ & $\begin{array}{l}\text { TTL Voltage } \\
\text { to/from } \\
\text { MAX232 }\end{array}$ \\
\hline $\begin{array}{l}\text { Data Transmission }(\mathrm{Rx} / \mathrm{Tx}) \\
\text { Logic } 0\end{array}$ & $\begin{array}{ll}+3 \mathrm{~V} & \text { to } \\
+15 \mathrm{~V} & \end{array}$ & $0 \mathrm{~V}$ \\
\hline $\begin{array}{l}\text { Data Transmission }(\mathrm{Rx} / \mathrm{Tx}) \\
\text { Logic } 1\end{array}$ & $\begin{array}{l}-3 \mathrm{~V} \text { to }- \\
15 \mathrm{~V}\end{array}$ & $5 \mathrm{~V}$ \\
\hline $\begin{array}{lr}\text { Control } & \text { Signals } \\
\text { (RTS/CTS/DTR/DSR) Logic } 0\end{array}$ & $\begin{array}{l}-3 \mathrm{~V} \text { to }- \\
15 \mathrm{~V}\end{array}$ & $5 \mathrm{~V}$ \\
\hline $\begin{array}{lr}\text { Control } & \text { Signals } \\
\text { (RTS/CTS/DTR/DSR) Logic } 1\end{array}$ & $\begin{array}{ll}+3 \mathrm{~V} & \text { to } \\
+15 \mathrm{~V} & \end{array}$ & $0 \mathrm{~V}$ \\
\hline
\end{tabular}




\subsection{ZIGBEE}

ZigBee technology is a low data rate technology, having low power consumption, low cost. Networking protocol targeted towards automation and remote control applications. IEEE committee started working on a low data rate standard. Then the ZigBee Alliance and the IEEE decided to join forces and ZigBee is the commercial name for this technology. ZigBee provides low cost and low power connectivity. These devices are expected to transmit 10-100 meters, depending on the RF environment and the power output consumption required for a given application that are required here. It will operate in the unlicensed RF worldwide as $2.4 \mathrm{GHz}$ global
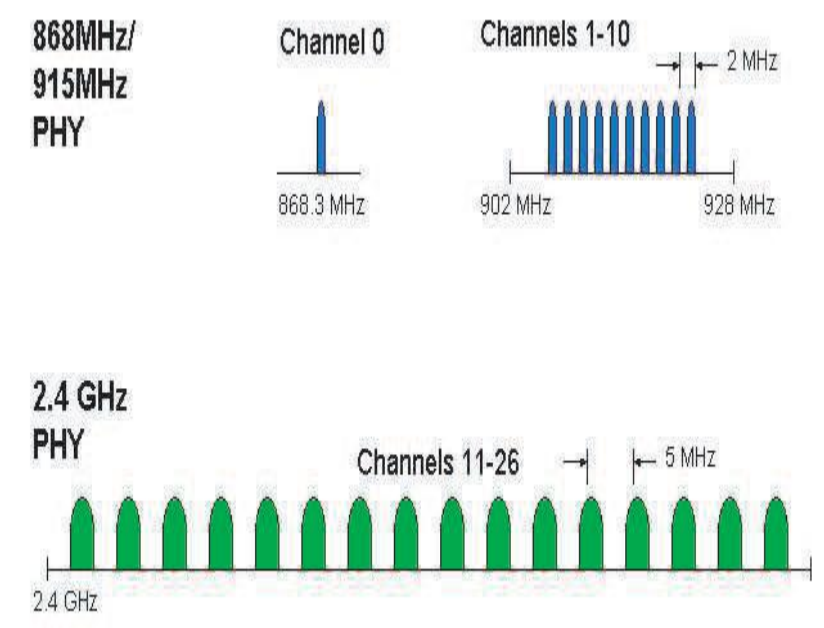

Fig 4: Operating Frequency Bands

\section{PROGRAMMING STEPS}

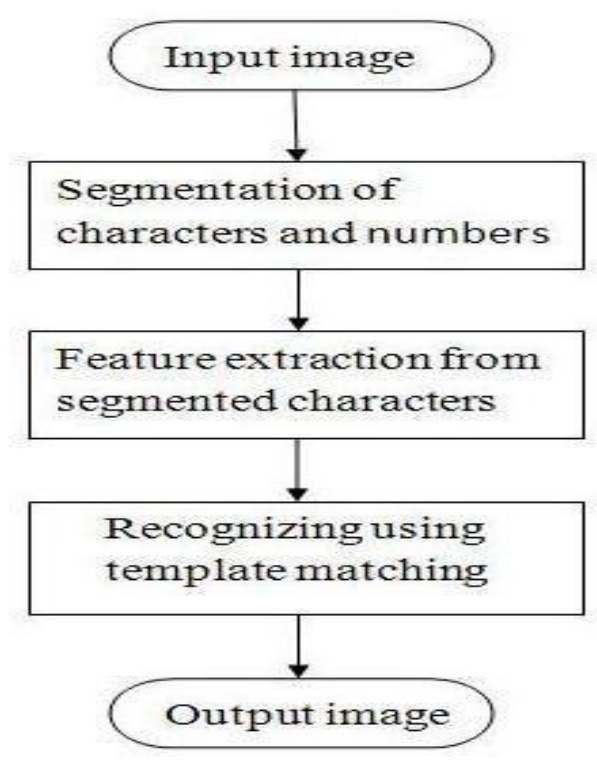

Fig 5: Programming Steps

The programming steps include segmentation of the image. From the segmented image the number is extracted ,that is the number is extracted from the image as characters. Then the number is matched to the template, if it is matched/unmatched corresponding character is send to the PIC. The steps of the programming are illustrated in the figure V.A

Though the system is used for the security purpose, the security level of the system can be improved by adopting the face recognition or through other identification techniques. This technology can be also used as a parking fee collecting system.

\section{FUTURE APPLICATIONS}

Though the system is used for the security purpose, the security level of the system can be improved by adopting the face recognition or through other identification techniques. This technology can be also used as a parking fee collecting system.

\section{CONCLUSION}

Number plate recognition can be made possible by the image identification technique[1]. This is the new technology that we have adapted in this project. This can be utilized in the security as well as in the industrial fields. The security level of the system is improved by implementing face recognition or other security levels.

\section{REFERENCES}

[1] International Journal of Advancements in Technology , Automatic Number Plate Recognition , S.Kranthi, K.Pranathi, A.Srisaila Information Technology, VR Siddhartha Engineering College, Vijayawada, India

[2] License Plate Identification Based on Image Processing Techniques W. K. I. L. Wanniarachchi 1D. U. J Sonnadara 2 and M. K. Jayananda 21 Department of Science and Technology, Uva Wellassa University, Sri Lanka 2 Department of Physics, University of Colombo, Sri Lanka

[3] AUTOMATIC NUMBER PLATE RECOGNITION Belal R. Mohamed*, Hala M. Abd El Kader, Hanaa M. Rafaat, Mohamed S. Sharaf

[4] IMAGE SEGMENTATION FRAMEWORK BASED ON MULTIPLEFEATURE SPACES Cong Liu Sch. of Opt.-Electr. \& Comput. Eng., Univ. of Shanghai for Sci. \& Technol., Shanghai, China Aimin Zhou ; Chunxue Wu ; Guixu Zhang

$\begin{array}{lcr}\text { LOCAL } & \text { BRIGHTNESS ADAPTIVE } & \text { IMAGE } \\ \text { COLOUR } & \text { ENHANCEMENT } & \text { WITH }\end{array}$
WASSERSTEIN DISTANCE Liqian Wang; Sch. of Comput. Sci. \& Eng., Nanjing Univ. of Sci. \& Technol., Nanjing, China ; Liang Xiao ; Hongyi Liu ; Zhihui Wei 